\title{
Sensoriamento remoto multiespectral para determinação de níveis de severidade de seca de ponteiros em Eucalyptus spp.
}

\author{
Multispectral remote sensing for determining dry severity levels of pointers \\ in Eucalyptus spp.
}

\author{
Leticia Daiane Pedrali ${ }^{1 *}$, Norton Borges Júnior ${ }^{2}$, Rudiney Soares Pereira ${ }^{1}$, \\ Juliana Tramontina ${ }^{3}$, Elisiane Alba ${ }^{1}$, Juliana Marchesan ${ }^{1}$
}

\section{RESUMO}

O objetivo deste trabalho foi desenvolver uma metodologia de processamento e análise de imagens obtidas por sensor multiespectral embarcado em RPA (Aeronave Remotamente Pilotada) para auxiliar na caracterização da resposta espectral de Eucalyptus urophylla $x$ E. grandis com incidência de seca de ponteiros causado pela bactéria Erwinia psidii. A metodologia consistiu em três etapas principais: obtenção das imagens digitais por meio do voo com RPA equipada com câmera multiespectral; caracterização dos níveis da doença em uma parcela de monitoramento em campo, e; processamento digital das imagens para obtenção de onze índices de vegetação comparados nos diferentes níveis de severidade e avaliados a partir dos testes estatísticos: Shapiro-Wilk, Levene, ANOVA, Kruskal-Wallis e Wilcoxon. Os testes indicaram que o Índice de Reflectância de Senescência das Plantas (PSRI) é o mais adequado para diferenciar os níveis de severidade da doença. A área saudável do talhão representou $30,38 \%$ da área de estudo, $17,48 \%$ é representado por entre linhas de plantio e solo exposto, enquanto que a área com algum nível de severidade da doença correspondeu a $52,14 \%$.
\end{abstract}

Palavras-chave: Eucalyptus spp. Índices de vegetação. Erwinia psidii.

\begin{abstract}
The objective of this work was to develop a methodology for the processing and analysis of images obtained by the multispectral sensor in a UAV (Unmanned Aerial Vehicle) to assist in the characterization of the spectral response of Eucalyptus urophylla $x$ E. grandis with an occurence of dry pointers caused by the bacterium Erwinia psidii. The methodology consisted of three main steps: obtaining the digital images through RPA flights, equipped with multispectral camera; characterization of disease levels in a plot of field monitoring, and; digital processing of the images to obtain eleven vegetation indexes, compared at different levels of severity, and evaluated using statistical tests: Shapiro-Wilk, Levene, ANOVA, Kruskal-Wallis and Wilcoxon. These indicated that the Plant Senescence Reflectance Index (PSRI) is the most adequate to differentiate the severity levels of the disease. The healthy area of the field represented $30.38 \%$ of the study area, $17.48 \%$ is represented by planting lines and exposed soil, while the area with some level of disease severity corresponded to $52.14 \%$.
\end{abstract}

Keywords: Eucalyptus spp. Vegetation index. Erwinia psidii.

\section{INTRODUÇÃO}

O gênero Eucalyptus, nativo do continente australiano, adaptou-se bem às condições climáticas brasileiras, o que possibilitou seu plantio em larga escala (GARLET et al., 2013). No entanto, com a introdução da monocultura no Brasil ocorreu o registro de pragas e doenças associadas às espécies plantadas. Dentre as bacterioses que incidem na cultura do eucalipto, a murcha e a seca de ponteiros, causadas por Erwinia psidii, tem surgido como uma das principais doenças em plantios comerciais de eucalipto, principalmente no Sul e Sudeste do Brasil (ARRIEL, 2012).

\footnotetext{
1. Departamento de Ciência Florestal, Universidade Federal de Santa Maria, UFSM. Santa Maria / RS, Brasil. * Autor correspondente: lepedrali@yahoo.com.br

2. Celulose Rio Grandense, CMPC. Guaíba / RS, Brasil.

3. Universidade Federal do Rio Grande do Sul, UFRGS. Porto Alegre / RS, Brasil.
}

Sci. For., Piracicaba, v. 47, n. 122, p. 224-234, jun. 2019 DOI: doi.org/10.18671/scifor.v47n122.05 
A bacteriose Erwinia psidii, é comumente conhecida por causar seca de ponteiros em goiabeira (Psidium guajava), que assim como o eucalipto pertence à família das Mirtáceas, indicando uma possível mudança de hospedeiro para se tornar um importante patógeno de Eucalyptus spp. (COUTINHO et al., 2011)

De acordo com as observações de Coutinho et al. (2011), as infecções devido a ocorrência de E. psidii causam graves danos às árvores jovens, especialmente através da morte de ponteiros e da perda de dominancia apical, no entanto as árvores também parecem se recuperar com relativa rapidez. Isto deve-se provavelmente ao seu crescimento rápido e devido a ocorrência da doença somente em árvores jovens, as quais possuem alto vigor vegetativo, que possibilita sua rápida recuperação. A respeito disso, a doença deve ser cuidadosamente monitorada.

Nesse sentido o sensoriamento remoto apresenta-se como uma ferramenta útil para essa finalidade, permitindo a avaliação e monitoramento de extensas áreas plantadas, de difícil acesso e em um curto espaço de tempo. A utilização de RPAs, por sua vez, possui ampla aplicabilidade, sobretudo pela obtenção de imagens com alta resolução espacial e temporal, se comparado com imagens de satélite disponíveis atualmente, servindo como base para a implementação de estratégias de manejo a curto ou a longo prazo, otimizando tempo e custo.

Dentre as aplicações que as imagens digitais possibilitam, os índices de vegetação (IV) se destacam devido à vasta aplicabilidade. Medeiros et al. (2008) recomendam o uso dos IVs, para o monitoramento de insetos desfolhadores e/ou doenças comprometedoras de área foliar. O grande desafio é, entretanto, encontrar um tratamento de imagem, ou um índice de vegetação, que consiga diagnosticar baixos níveis de desfolhamento ou infestação, além de caracterizar o estado sanitário de uma floresta.

Diante da problemática exposta, o objetivo deste trabalho foi desenvolver uma metodologia de processamento e análise de imagens obtidas por sensor multiespectral embarcado em RPA, para auxiliar na caracterização da resposta espectral de E. urophylla $x$ E. grandis com incidência de seca de ponteiros, visando a discriminação e reconhecimento dos níveis de severidades da doença em plantios florestais.

\section{MATERIAL E MÉTODOS}

O trabalho foi realizado em etapas de campo e outra de laboratório, o qual tem suas atividades especificadas no fluxograma apresentado na Figura 1.

A área de estudo localiza-se no município de Minas do Leão - RS. A área plantada de Eucalyptus sp. no município corresponde a 4.700 hectares (IBGE, 2016). De acordo com a classificação de Köppen o clima da região é Subtropical Úmido (Cfa), com temperaturas médias que variam entre $18^{\circ} \mathrm{C}$ e $20^{\circ} \mathrm{C}$, com precipitações distribuídas durante o ano, apresentando média anual de $1.950 \mathrm{~mm}$ (ALVARES et al., 2013).

A área de estudo (Figura 2) possui 14,09 hectares, correspondendo a aproximadamente 0,3\% da área do município, com plantio do Eucalyptus urophylla $x$ Eucalyptus grandis o qual foi plantado em maio de 2015, com espaçamento de 2,15 m X $3 \mathrm{~m}$, possuindo 14 meses de idade na data do levantamento (08/07/2016). Desde os primeiros meses, após o plantio, foi relatado a ocorrência da seca de ponteiros sendo o agente etiológico da doença identificado como a bactéria Erwinia psidii.

O levantamento de campo, se baseou em observações de plantas infectadas em dez linhas de plantio, localizadas em uma parcela de monitoramento de aproximadamente $785 \mathrm{~m}^{2}$. Os vértices da parcela foram levantados com o GPS Garmin eTrex 20 e 12 árvores aleatórias dentro da parcela foram localizadas com GPS RTK. As 95 árvores avaliadas individualmente foram classificadas em quatro níveis de severidade pré-estabelecidos, adaptados da escala proposta por Ferreira (1989), para avaliar a seca de ponteiros de eucalipto, sendo: 1) sem ocorrência da doença; 2) pequena ocorrência da doença: menos de 30\% da copa da árvore afetada; 3 ) média ocorrência da doença: até 50\% da copa da árvore afetada; 4) alta ocorrência da doença: acima de 50\% da copa da árvore afetada.

O levantamento aéreo para a obtenção das imagens foi realizado no mesmo dia, por volta das 11 horas e 15 minutos, com as condições climáticas favoráveis ao voo. O céu estava parcialmente nublado, com temperatura mínima de $7,7^{\circ} \mathrm{C}$ e máxima de $17,7^{\circ} \mathrm{C}$, com umidade relativa do ar de $73,25 \%$ e ventos com velocidade de $1,1 \mathrm{~m} / \mathrm{s}$ (INMET, 2016). 
Pedrali et al. - Sensoriamento remoto multiespectral para determinação de níveis de severidade de seca de ponteiros em Eucalyptus spp.

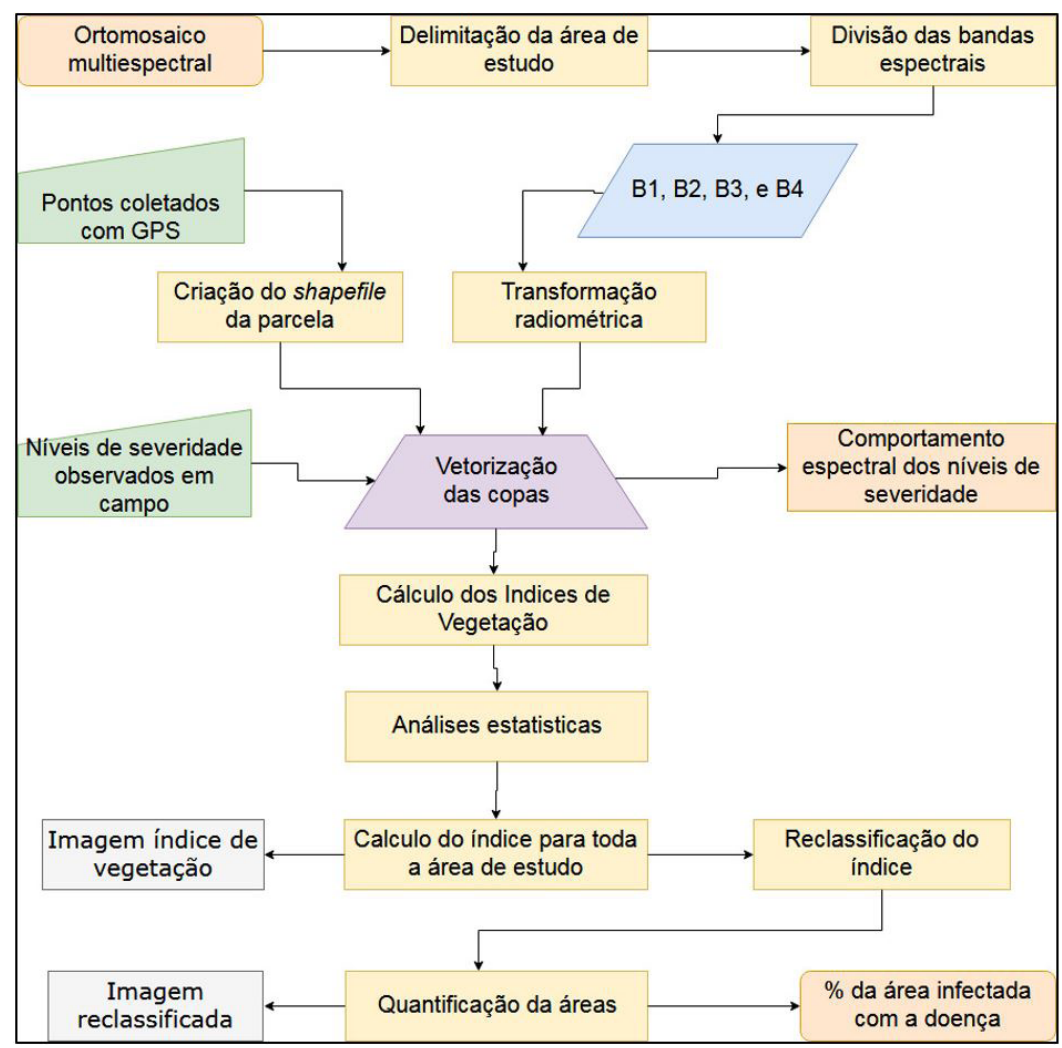

Figura 1 - Fluxograma de atividades realizadas neste estudo.

Figure 1 - Flowchart of activities carried out in this study.
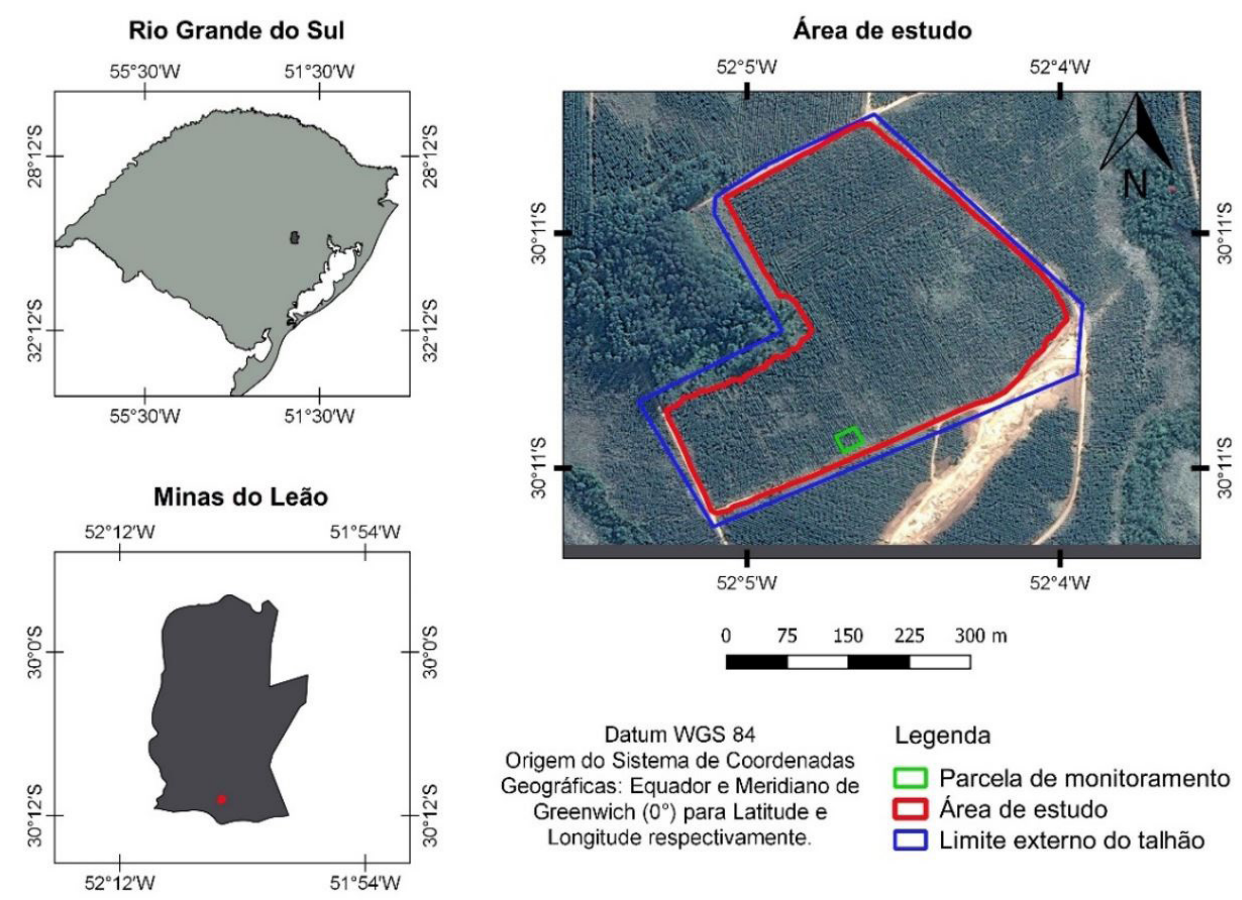

Figura 2 - Localização da área de estudo.

Figure $\mathbf{2}$ - Location of the study area.

O RPA utilizado no levantamento aéreo foi equipado com o sensor multibandas Parrot Sequoia MicaSense que possui 4 bandas espectrais: verde $(550 \mathrm{~nm})$, vermelho $(660 \mathrm{~nm})$, Rededge $(735 \mathrm{~nm}) \mathrm{e}$ Infravermelho Próximo $(790 \mathrm{~nm})$. O voo realizado teve as seguintes características: velocidade média: $18 \mathrm{~m} / \mathrm{s}$; altitude: $80 \mathrm{~m}$; sobreposição longitudinal e lateral de imagens: $70 \%$; resolução espacial: $10 \mathrm{~cm}$ e precisão horizontal: $30 \mathrm{~cm}$. Foram tomadas 2.196 imagens em 549 pontos e 14 linhas de voo, em 
um tempo médio de voo de 17 minutos. Os mosaicos gerados foram processados no software QGIS 2.16.2 em um projeto com sistema de referência WGS 84 .

A partir dos pontos levantados com o GPS Garmin e RTK foi possível localizar na imagem as 95 árvores com possível ataque da doença identificadas na parcela de monitoramento. Cada uma das árvores teve sua copa vetorizada manualmente sobre a imagem multiespectral, sendo os vetores separados de acordo com os níveis de severidade observados em campo, com isso foi possível avaliar as respostas espectrais de cada nível a partir da média dos valores de números digitais (ND) em cada banda do sensor. Sabendo-se que a utilização dos números digitais para cálculos dos índices não permite uma análise quantitativa dos dados, realizou-se apenas uma análise qualitativa dos IVs estudados.

Foram selecionados 11 IVs, que refletem o estado fisiológico das plantas, discriminados na Tabela 1. Esses índices foram calculados inicialmente para as áreas de copas que foram vetorizadas sobre a área da imagem correspondente à parcela de monitoramento.

Para as análises estatísticas utilizou-se o programa RGui 3.3.2. pacote "car". No qual os valores médios dos $11 \mathrm{IVs}$ foram analisados quanto a sua condição de distribuição normal pelo teste de Shapiro-Wilk. Para verificar a homogeneidade da variância dos dados foi utilizado o teste de Levene, e posteriormente foi realizada a Análise da Variância (ANOVA). Com base nos dados obtidos na ANOVA, procedeu-se com os testes de Kruskal-Wallis e Wilcoxon. O IV considerado significativo pelas análises estatísticas foi aplicado para a área total de estudo, em seguida foram realizados testes de reclassificação do IV utilizando-se 4, 5, 6, 8, 10, 20, 35 e 137 classes de intervalos iguais baseados nos valores de mínimo, máximo, média e desvio padrão do índice e, também, nos valores de resposta espectral de cada nível de severidade da doença.

Tabela 1 - Índices de vegetação utilizados no estudo.

Table 1 - Vegetation indexes used in the study.

\begin{tabular}{|c|c|c|c|c|}
\hline & Nome & Descrição & Autor & Formula \\
\hline 1. & NDVI & $\begin{array}{l}\text { Índice de vegetação da diferença } \\
\text { normalizada }\end{array}$ & Rouse et al. (1974) & $\frac{(\text { NIR-Red) }}{(\text { NIR+RED) }}$ \\
\hline 2. & SR & Razão simples & Rouse et al. (1974) & $\frac{\text { NIR }}{\text { Red }}$ \\
\hline 3. & SAVI* & $\begin{array}{l}\text { Índice de vegetação ajustado para } \\
\text { solo }\end{array}$ & Huete (1988) & {$\left[\frac{(\mathrm{NIR}-\mathrm{Red})}{(\mathrm{NIR}+\mathrm{Red}+\mathrm{L})}\right]+(1+\mathrm{L})$} \\
\hline 4. & $\mathbf{N D V I}_{\text {Rededge }}$ & $\begin{array}{l}\text { Índice de vegetação da diferença } \\
\text { normalizada com a banda } \\
\text { Rededge }\end{array}$ & Gitelson e Merzlyak (1994) & $\frac{\text { (NIR-Rededge) }}{\text { (NIR+Rededge) }}$ \\
\hline 5. & GNDVI & $\begin{array}{l}\text { Índice de vegetação da diferença } \\
\text { normalizada no verde }\end{array}$ & Gitelson, Kaufman e Merlyak (1996) & $\frac{(\text { NIR-Green) }}{(\text { NIR+Green })}$ \\
\hline 6. & RVI & Índice de vegetação reverso & Jacobsen et al. (1998) & $\frac{\text { Red }}{\text { NIR }}$ \\
\hline 7. & PSRI & $\begin{array}{l}\text { Índice de reflectância de } \\
\text { senescência das plantas }\end{array}$ & Merzlyak et al. (1999) & $\frac{(\text { Red-Green) }}{\text { Rededge }}$ \\
\hline 8. & MTCI & Índice terrestre de clorofila & Dash e Curran (2004) & $\frac{\text { (NIR-Rededge) }}{\text { (Rededge-Red) }}$ \\
\hline 9. & $\mathrm{CL}_{\text {green }}$ & Índice verde de clorofila & Gitelson et al. (2005) & $\left(\frac{\mathrm{NIR}}{\text { Green }}\right)-1$ \\
\hline 10. & $\mathrm{CL}_{\text {Rededge }}$ & Índice Rededge de clorofila & Gitelson et al. (2005) & $\left(\frac{\mathrm{NIR}}{\text { Rededge }}\right)-1$ \\
\hline 11. & VIOPT $_{2}$ & Índice de vegetação otimizado 2 & Jasper et al. (2009) & $\frac{\text { NIR }}{\text { Rededge }}$ \\
\hline
\end{tabular}

*Para a computação do índice SAVI foram utilizados os valores de $L=0,50$ e $L=I$.

*For the computation of the $S A V I$ index the values $L=0.50$ and $L=I$ were used. 
Pedrali et al. - Sensoriamento remoto multiespectral para determinação de níveis de severidade de seca de ponteiros em Eucalyptus spp.

\section{RESULTADOS E DISCUSSÕES}

\section{Levantamento de campo}

O levantamento de campo resultou na coleta de dados sobre 95 árvores, quanto à sua classificação de severidade da doença, registrados em uma tabela de campo e sintetizados na Tabela 2.

Tabela 2 - Ocorrência de indivíduos em cada nível de severidade da doença.

Table 2 - Occurrence of individuals at each level of disease severity.

\begin{tabular}{clrr}
\hline $\begin{array}{c}\text { Nível de } \\
\text { severidade }\end{array}$ & \multicolumn{1}{c}{ Descrição } & $\begin{array}{c}\mathbf{N}^{\circ} \\
\text { indivíduos }\end{array}$ & $\%$ \\
\hline 1 & Sem ocorrência de seca de ponteiros & 34 & 35,78 \\
2 & Pequena ocorrência de seca de ponteiros: menos de 30\% da copa afetada & 40 & 42,10 \\
3 & Média ocorrência de seca de ponteiros: até 50\% da copa afetada & 20 & 21,05 \\
4 & Alta ocorrência de seca de ponteiros: acima de 50\% da copa afetada & 1 & 1,05 \\
\hline
\end{tabular}

Em geral, os sintomas da doença observados em campo caracterizam-se por seca de ponteiros nos ramos jovens das plantas. Além disso, observou-se a necrose do pecíolo e da nervura central das folhas maduras que posteriormente murcham e secam, como pode ser observado na Figura 3.

As plantas consideradas em nível 2 de severidade apresentaram secamento apenas na parte superior da copa, enquanto que no nível 3 de severidade o secamento dos ramos jovens é maior, levando a perda parcial das folhas. As árvores em nível 4 de severidade apresentaram secamento mais severo dos ramos, com perda de folhas acima de $50 \%$.

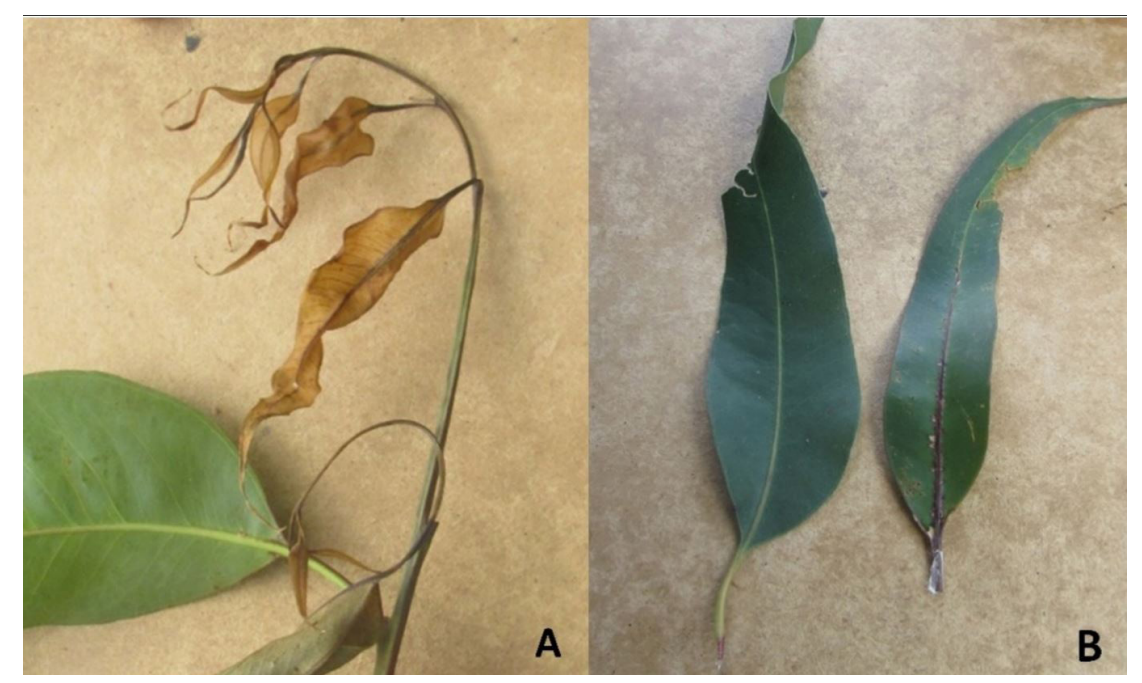

Figura 3- Detalhe dos sintomas de E. psidii em Eucalyptus urophylla x E. grandis A) Secamento de folhas jovens; B) Necrose do pecíolo e nervura principal em folha madura comparada com uma folha sem sintoma da doença.

Figure 3- Symptoms details of E. psidii in Eucalyptus urophylla $x$ E. grandis A) Drying of young leaves; B) Petiole necrosis and main vein in mature leaf compared to a leaf without symptom of the disease.

\section{Levantamento aéreo}

O levantamento aéreo resultou em um ortomosaico georreferenciado, com precisão horizontal de $30 \mathrm{~cm}$, composto pelas bandas: verde (B1), vermelho (B2), Redege (B3) e Infravermelho Próximo (B4). Com os valores médios dos níveis digitais das 95 árvores classificadas de acordo com os níveis de severidade (N1, N2, N3, N4), construiu-se o gráfico da assinatura espectral simulada (Figura 4).

O comportamento espectral dos níveis de severidade é caracterizado por valores médios de reflectância na banda 1 , seguido por uma redução na banda 2 e aumento progressivo nas bandas 3 e 4 . Esse comportamento segue a assinatura espectral típica das folhas verdes, em que há maior reflectância na região do verde, baixa reflectância na região do vermelho e aumento da reflectância da borda do vermelho (Rededge) em direção ao Infravermelho Próximo. 


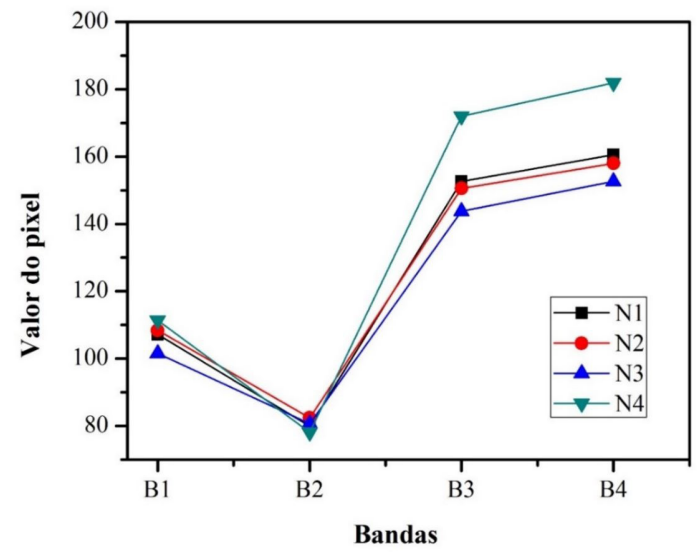

Figura 4 - Média dos ND de acordo com níveis de severidade nas 4 bandas espectrais do sensor Sequoia. Figure 4 - Mean of DN according to severity levels in the 4 spectral bands of the Sequoia sensor.

Analisando-se as curvas de refletância apresentadas na Figura 4, observa-se que os níveis de severidade 1 e 2 apresentam valores de reflectância similares ao longo da região do espectro eletromagnético avaliado, a diferenciação destes níveis é dificultada pela semelhança verificada nas respostas espectrais.

O nível 3 de severidade apresenta uma leve redução de reflectância nas bandas 1, 3 e 4 em relação a todos os outros níveis. Considerando esse nível com ocorrência média da doença pode-se dizer que a planta está sob estresse moderado. Nesta situação, ocorre o fechamento estomático e a redução da atividade fotossintética (SMIGAJ et al., 2015) o que acarreta a redução da reflectância na região do verde.

Sendo o nível 3 representado por um número maior de indivíduos, a influência da estrutura das camadas de folhas, além do arroxeamento dos pecíolos e as manchas de aspecto encharcado observadas nas folhas mais maduras presentes principalmente no terço inferior da copa, pode ter acarretado na grande diferença verificada na assinatura espectral desse nível.

O nível 4 de severidade possui maior reflectância nas bandas 1, 3 e 4, em comparação com os outros níveis, a maior reflectância na banda 1 é explicada devido a menor atividade fotossintética que ocorre com a senescência das plantas (MOREIRA, 2007). Apenas na banda 2 possui a reflectância reduzida, uma vez que esta banda corresponde a faixa espectral do vermelho (660 nm), região que ocorre maior absorção de clorofila presente nas folhas.

O indivíduo do nível 4 de severidade possui menor quantidade de folhas, devido ao secamento e queda causados pela doença, o que aumenta a exposição dos galhos e troncos ou ainda das próprias folhas secas presas à arvore, influenciando o comportamento espectral, dessa forma, a presença desses constituintes pode ter influenciado o aumento da reflectância na região do Infravermelho Próximo. Segundo Asner (1998), para os galhos, a variação na reflectância vai de $20 \%$ a $45 \%$, acarretando a maior reflectância no Infravermelho Próximo e menor na região do visível. Para Ponzoni et al. (2012), a saída da água das folhas acarreta na degradação das proteínas e pigmentos fotossintetizantes, o que tornará a folha menos apta a absorver radiação eletromagnética e isso resultará no aumento dos valores de reflectância.

No caso da ocorrência de Erwinia psidii, a média de reflectância simulada do nível 4 de severidade diferenciou-se dos demais. Resultados similares foram obtidos por Lippert (2011), ao avaliar folhas da porção superior da copa de Eucalyptus globulus, atacadas com Mycosphaerella spp., onde encontrou diferença significativa no comportamento espectral na região do Infravermelho Próximo e visível para o nível "muito" (nível 4), na estação climática do inverno.

\section{Índices de vegetação}

Os valores médios dos índices obtidos para as 95 árvores vetorizadas nos quatro níveis de severidade de seca de ponteiros são apresentados na Figura 5. Cada índice possui um objetivo e uma característica específica, porém, podemos analisa-los agrupando-os segundo suas generalidades, por exemplo, os índices que utilizam a banda rededge: VIOPT ${ }_{2}, \mathrm{MTCI}, \mathrm{PSRI}, \mathrm{NDVI}_{\text {rededge' }}$ são índices designados para caracterizar variações espectrais associadas com a posição da borda vermelha, a qual pode ser afetada 


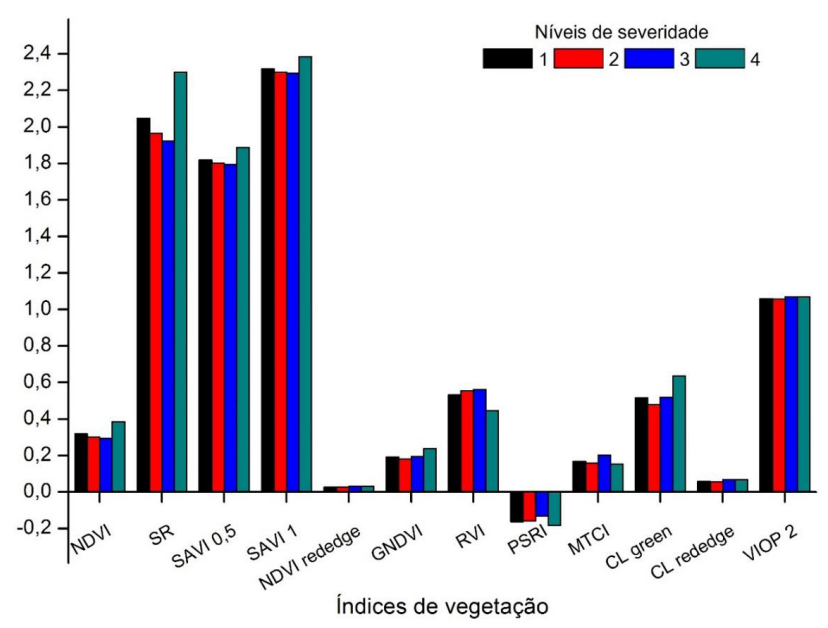

Figura 5 - Valores médios dos índices de vegetação de acordo com os níveis de severidade. Figure $\mathbf{5}$ - Mean values of vegetation indexes according to severity levels.

por variações no conteúdo de clorofila e água nas folhas. Enquanto que em sentido amplo, NDVI, SR, RVI, GNDVI e $\mathrm{CL}_{\text {green }}$ são índices relacionados aos pigmentos foliares (SOUZA et al., 2009) e biomassa.

Segundo Apan et al. (2003), vários IVs são funcionalmente redundantes em conteúdo de informação, dificultando sua escolha para finalidades específicas. Isso foi verificado neste estudo, visto que alguns índices apresentam comportamentos semelhantes, como por exemplo os índices do primeiro grupo, $\mathrm{NDVI}_{\text {rededge }}$ e VIOPT 2 com médias decrescendo do nível 1 ao nível 2, crescendo para o nível 3 e com pouca alteração para o nível 4. Já no segundo grupo, NDVI e SR apresentaram comportamentos semelhantes, corroborando com a informação de Jensen (2009) que o NDVI é funcionalmente equivalente ao SR, estes índices tiveram suas médias decrescendo nos níveis 1,2 e 3 o que indica redução da quantidade de folhas, no entanto apresentaram maior média para o nível 4, tal resultado pode ter sido influenciado pela presença de vegetação rasteira abaixo da área da copa.

\section{Análises estatísticas}

Segundo o teste de Shapiro-Wilk, os índices PSRI e SR não apresentaram normalidade. Segundo o teste de Levene, todas as médias possuem homogeneidade das variâncias. Na Análise da variância, ao nível de $95 \%$ de confiança, nenhum índice foi considerado significativo. Pelo teste não paramétrico de Kruskal-Wallis, o índice PSRI apresentou diferença significativa, ao nível de 0,05\% de confiança, e com base nesse resultado foi realizado o teste de Wilcoxon para o índice PSRI.

Pela análise da aplicação do teste de Wilcoxon, os resultados mostraram que os valores médios de PSRI diferiram significativamente entre os grupos $1 \times 3$ e grupos $2 \times 3$. Esse resultado indica que este índice é útil para diferenciar as árvores com a seca de ponteiros nos diferentes níveis de severidade estabelecidos.

Analisando-se a média do índice PSRI em cada nível de severidade, observa-se que do nível 1 ao nível 3 ocorre um aumento gradativo de -0,163 para -0,131. Em seguida, esta média decresce para -0,182 no nível 4. Segundo Ren, Chen e An (2017) o valor de PSRI aumenta durante a senescência foliar devido ao aumento na proporção de carotenóides para clorofilas. Isso é observado neste estudo com o aumento do nível da severidade, até o nivel 3, no entanto o decrescimo no nível 4 indica a redução dessa porporção, porém estisticamente esta classe não pode ser diferenciada das demais.

Os pigmentos exercem imporante função foliar, suas variações podem fornecer informações sobre o estado fisiológico das folhas, o índice PSRI é sensível à retenção ou acúmulo de carotenóides nas folhas senescentes e nos frutos de maturação (MERZLYAK et al., 1999), sendo assim, acredita-se que este seja o principal fato que torna este índice capaz de diferenciar os níveis de severidade da doença. Desse modo, a aplicação do PSRI para a área de estudo total é demostrado na seção a seguir.

\section{Índice de Reflectância de Senescência das Plantas (PSRI)}

Aplicado à área total de estudo, o índice PSRI apresentou valor médio de -0,043, com variação entre -1,747 e 1,983. Com o uso desse índice, observou-se que houve realce de algumas feições, como as áreas de solo exposto, realçando as falhas de plantio e as áreas sadias (Figura 6). As áreas 


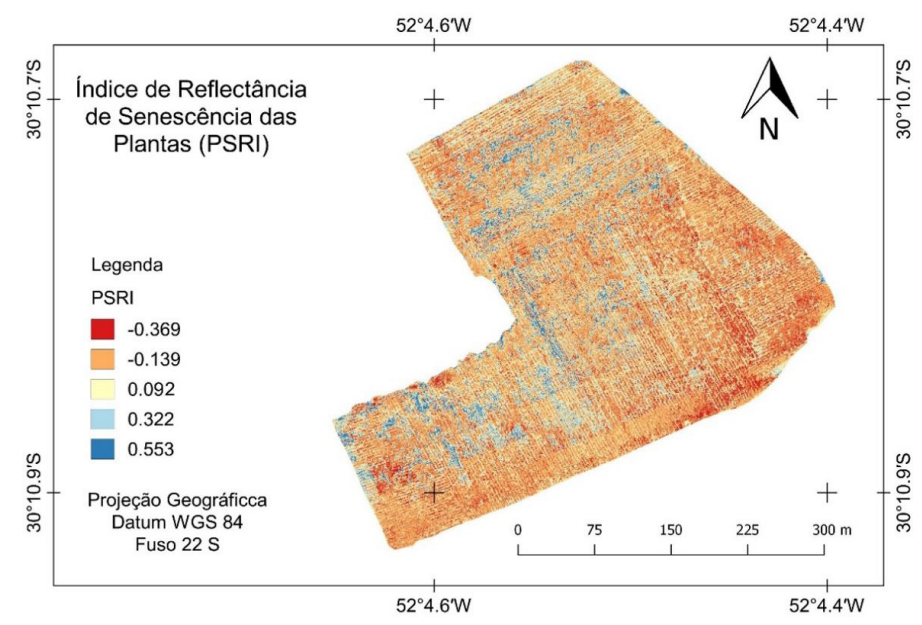

Figura 6 - Índice de Reflectância de Senescência das Plantas para todo o talhão.

Figure 6 - Plant Senescence Reflectance Index for the entire field.

infectadas pela bacteriose apresentaram tonalidade vermelho claro com variação ao laranja, o que indica o aumento do PSRI.

No intuito de avaliar a saúde do talhão foram realizados testes para a reclassificação do índice PSRI, sendo que o teste com 5 classes foi considerado o ideal para realizar a separabilidade dos níveis de severidade e realizar a quantificação dos pixels, determinando assim a área recoberta com cada classe proposta. A Tabela 3 apresenta os valores dos limites superior e inferior de cada classe, sua quantificação em hectares e sua representação em porcentagem da área total de estudo.

Tabela 3 - Classes definidas para reclassificação do índice PSRI, seus respectivos valores e área em hectares.

Table 3 - Classes defined for reclassification of the PSRI index, their respective values and area in hectares.

\begin{tabular}{ccccc}
\hline Classe & Limite inferior & Limite superior & Área em ha & $\%$ \\
\hline $\mathbf{1}$ & $-1,7472$ & $-0,1673$ & 4,28 & 30,38 \\
$\mathbf{3}$ & $-0,1673$ & $-0,1398$ & 1,09 & 7,75 \\
$\mathbf{3}$ & $-0,1398$ & $-0,1124$ & 1,05 & 7,45 \\
$\mathbf{4}$ & $-0,1124$ & 0,1349 & 5,20 & 36,94 \\
$\mathbf{5}$ & 0,1349 & 1,9831 & 2,46 & 17,47 \\
& & Total: $\mathbf{1 4 , 0 9}$ & & $\mathbf{1 0 0}$ \\
\hline
\end{tabular}

A imagem reclassificada é apresentada na Figura 7. Observa-se que no mapa são representadas 5 classes, sendo a classe 1 representada pela vegetação saudável, ou seja, sem a ocorrência da doença, correspondendo a 30,38\%. A classe 2 representa a vegetação com nível de severidade 2 . A classe 3 abrange a vegetação com nível 3 de incidência de seca de ponteiros. A classe 4, compreende áreas consideradas com baixa cobertura de folhas e início de transição para solo exposto, essas classes são observadas principalmente nas regiões de bordadura das copas, representadas no mapa com a coloração laranja, e a classe 5 representa as áreas de solo exposto, falhas e entrelinhas de plantio e corresponde a 17,47\% da área de estudo.

As classes que apresentam algum nível de severidade da doença e que estatisticamente são diferenciáveis, são 2 e 3, que juntas representam 15,2\% da área de estudo, no entanto ainda existe a classe 4, que numericamente não corresponde ao valor do índice da copa amostrada, no entanto, analisando-se o comportamento do índice, sabe-se que abrange indivíduos com níveis de severidade superiores, esta classe representa 36,95\% da área de estudo.

Nesse estudo, observou-se o aumento do índice PSRI conforme o aumento das classes de severidade, devido principalmente ao secamento das folhas, que possuem comportamento semelhante ao das folhas senescentes, exceto na classe 4. Merzlyak et al. (1999), na pesquisa com o indice PSRI em Coleus blumei, verificou que quando a relação carotenoides / clorofila aumentou, o índice também aumentou. Do mesmo modo, durante a senescência das folhas de bordo, tanto a relação carotenoides / clorofila quanto o PSRI sofreram um aumento acentuado. 
Pedrali et al. - Sensoriamento remoto multiespectral para determinação de níveis de severidade de seca de ponteiros em Eucalyptus spp.

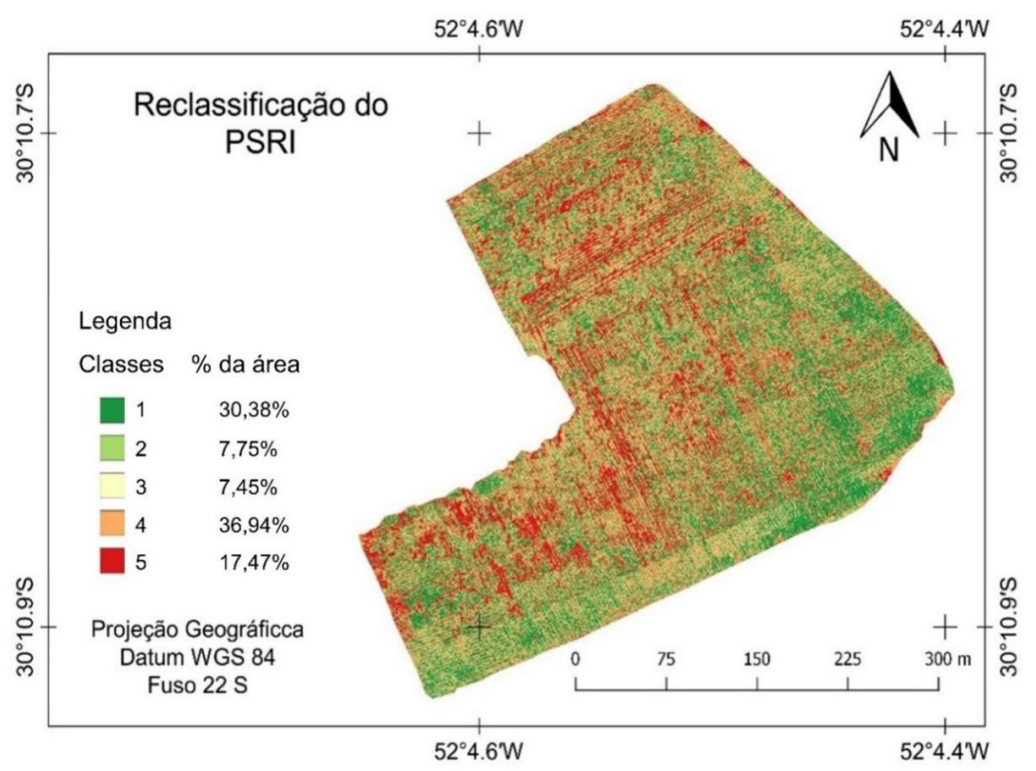

Figura 7 - Imagem reclassificada nas 5 classes e sua porcentagem.

Figure 7 - Reclassified image in the 5 classes and their percentage.

O estudo de Ren, Chen e An (2017) fez a primeira tentativa de calcular o índice PSRI usando dados de sensoriamento remoto por satélite e avaliar a confiabilidade do PSRI no monitoramento da fenologia da vegetação no norte da China, concluindo que o PSRI tem sensibilidade semelhante à dinâmica da vegetação com NDVI tanto na primavera como no outono, portanto, é complementar ao NDVI na descrição da fenologia da vegetação. No entanto, neste trabalho, o NDVI não teve sensibilidade semelhante ao PSRI, isso porque eles foram avaliados isoladamente quanto aos níveis de severidade da doença, não sendo comparados em área total do plantio.

\section{CONCLUSÃO}

A metodologia de levantamento de imagens com o uso de RPA, processamento e análise proposta para auxiliar na caracterização da resposta espectral de Eucalyptus urophylla $x$ Eucalyptus grandis com incidência de seca de ponteiros, mostrou-se satisfatória na discriminação e no reconhecimento dos níveis de severidades da doença em plantios florestais.

A avaliação da severidade da doença com as imagens, a partir da relação de IVs aos níveis de severidade encontrados em levantamento de campo, mostrou-se eficiente para quantificar a área afetada com algum nível de severidade na área de estudo. Dentre os índices testados, o Índice de Reflectância de Senescência das Plantas (PSRI) destacou-se na avaliação das copas infectadas, para diferenciar as árvores entre os níveis 1 e 3 e entre os níveis 2 e 3 de severidade.

Aplicado à área total do talhão, o PSRI evidenciou as áreas de solo exposto, bem como as regiões do talhão consideradas saudáveis, permitindo a quantificação das áreas com problemas relacionados à ocorrência da seca de ponteiros em eucalipto.

O RPA equipado com o sensor multibandas mostrou-se eficaz para a geração de imagens capazes de evidenciar a presença de estresse em plantios florestais. O aumento da resolução espacial e temporal, a possibildiade de análise das copas individualizadas, além de sua facilidade de manuseio e rapidez na aquisição de dados proporcionados pelo uso da RPA, são características que irão provavelmente converter o seu uso como uma importante ferramenta para a silvicultura, ainda que sejam necessários esforços para tornar essa tecnologia mais acessível e disponível para os usuários, abrangendo diferentes interesses para a avaliação das culturas.

\section{REFERÊNCIAS}

ALVARES, C. A.; STAPE, J. L.; SENTELHAS, P.C.; GONÇALVES, J. L. M.; SPAROVEK, G. Koppen's climate classification map for Brazil. Meteorologische Zeitschrift, Stuttgart, v. 22, n. 6, p. 711-728, 2013. 
APAN, A.; HELD, A.; PHINN, S.; MARKLEY, J. Formulation and assessment of narrow-band vegetation indices from EO-1 Hyperion imagery for discriminating sugarcane disease. In: Spatial Sciences Institute Biennial Conference: Spatial Knowledge Without Boundaries, 2003. Proceedings... Canberra: SSC, 2003. p. 1-13.

ARRIEL, D. A. A. Seca de ponteiros de Eucalyptus spp. causada por Erwinia psidii no Brasil. 2012. 40 p. Dissertação (Mestrado em Genética e Melhoramento) - Universidade Federal de Viçosa, Viçosa, 2012.

ASNER, G. P. Biophysical and biochemical sources of variability in canopy reflectance. Remote Sensing of Environment. v. 64, n. 3, p. 234-253, 1998.

COUTINHO, T. A.; BRADY, C. L.; VAART, M.; VENTER, S. N.; TELECHEA, N.; ROLFO, M.; PEREZ, C.; WINGFIELD, M. J. A new shoot and stem disease of eucalyptus species caused by Erwinia psidii. Australasian Plant Pathology, v. 40, n. 1, p. 55-60, 2011.

DASH, J.; CURRAN, P.J. The MERIS terrestrial chlorophyll index. International Journal of Remote Sensing, v. 25, p. 5403-5413, 2004.

FERREIRA, F. A. Patologia Florestal: principais doenças florestais no Brasil. Viçosa: Sociedade de Investigações Florestas, 570 p. 1989.

GARLET, J.; COSTA, E. C.; BOSCARDIN, J.; DEPONTI, G.; SHWENGHER, C. R.; MACHADO, L. M. Leptocybe invasa em Eucalyptus sp. no estado do Rio Grande do Sul, Brasil. Ciência Rural, Santa Maria, v. 43, n. 12, p. 2175-2177, 2013.

GITELSON, A. A.; MERZLYAK, M. N. Spectral reflectance changes associate with autumn senescence of Aesculus hippocastanum L. and Acer platanoides L. leaves. Spectral features and relation to chlorophyll estimation. Journal of Plant Physiology, Melbourne, v. 143, p. 286-292 1994.

GITELSON, A. A.; KAUFMAN, Y. J.; MERZLYAK, M. N. Use of a green channel in remote sensing of global vegetation from EOS-MODIS. Remote Sensing Environment. v. 58, p. 289-298, 1996.

GITELSON, A. A.; VINÃ, A.; CIGANDA, V.; RUNDQUIST, D. C.; ARKEBAUER, T. J. Remote estimation of canopy chlorophyll content in crops. Geophysical Research Letters, v. 32, n. 8, p. 1-4, 2005.

HUETE, A.R. A soil-adjusted vegetative index (SAVI). Remote Sensing Environment. v. 25, p. 295-309. 1988.

IBGe - INSTITUTO BRASILEIRO DE GEOGRAFIA E eSTATÍSTICA. Produção da Extração Vegetal e da Silvicultura. 2016. Disponível em:< https://sidra.ibge.gov.br/Tabela/5930\#resultado >. Acesso em: 08 jun. 2018.

INMET - INSTITUTO NACIONAL DE METEOROLOGIA. Banco de Dados Meteorológicos para Ensino e Pesquisa. 2016. Disponível em: < http://www.inmet.gov.br/portal/index.php?r=bdmep/bdmep >. Acesso em: 03 dez. 2016.

JACOBSEN, S.; P. H., JENSENS, C. R. Reflectance Measurements, a quick and non-destructive technique for use in agricultural research. In: INTERNATIONAL CONFERENCE ON SUSTAINABLE AGRICULTURE IN TROPICAL AND SUBTROPICAL HIGHLANDS WITH SPECIAL REFERENCE TO LATIN AMERICA (SATHLA). Anais...Rio de Janeiro: SATHLA, 1998.

JASPER, J.; REUSCH, S.; LINK, A. Active sensing of the $\mathrm{N}$ status of wheat using optimized wave- length combination: Impact of seed rate, variety and growth stage. In: E. J. VAN HENTEN; D. GOENSE, C. LOKHORST (Eds.). EUROPEAN CONFERENCE ON PRECISION AGRICULTURE. 7., 2008, Wageningen. Proceedings... Wageningen: ECPA, 2009. p.23-30.

JENSEN, J. R. Sensoriamento Remoto do Ambiente: uma perspectiva em recursos terrestres. 2. ed. São José dos Campos, SP: Parêntese, 2009. 672 p.

LIPPERT, D. B. Resposta espectral de folhas de Eucalyptus globulus (Labill.) atacadas por Mycosphaerella spp. 2011. 64 p. Dissertação (Mestrado em. Universidade Federal de Santa Maria, Santa Maria, 2011.

MEDEIROS, F. A.; ALONÇO, A. S.; BALESTRA, M. R. G.; DIAS, V. O.; LANDERHAL JÚNIOR, M. L. Utilização de um veículo aéreo não-tripulado em atividades de imageamento Georeferenciado. Revista Ciência Rural, Santa Maria, v. 38, n. 8, p. 2375- 2378, 2008.

Sci. For., Piracicaba, v. 47, n. 122, p. 224-234, jun. 2019 DOI: doi.org/10.18671/scifor.v47n122.05 
Pedrali et al. - Sensoriamento remoto multiespectral para determinação de níveis de severidade de seca de ponteiros em Eucalyptus spp.

MERZLYAK, M. N.; GITELSON, A. A.; CHIVKUNOVA, O. B.; RAKITIN, V. Non-destructive optical detection of pigment changes during leaf senescence and fruit ripening. Physiologia Plantarum, Lund, v. 106, n. 1, p. 135-141, 1999.

MOREIRA, M. A. Fundamentos do sensoriamento remoto e metodologias de aplicações. 3. ed. Viçosa: Editora UFV, 2007. 320 p.

PONZONi, F. J.; SHIMABUKURO, Y. E. Sensoriamento Remoto no Estudo da Vegetação. São José dos Campos: Editora Parêntese, 2007.

REN, S., CHEN, X.; AN, S. Assessing plant senescence reflectance index-retrieved vegetation phenology and its spatiotemporal response to climate change in the Inner Mongolian Grassland. International Journal of Biometeorology, v. 61, n. 4, p. 601-612, 2017.

ROUSE, J. W.; HAAS, R. H.; SCHELL, J. A. Monitoring vegetation systems in the Great Plains with ERTS. In: ERTS-1 SYMPOSIUM, 3., 1973, Washington. Proceedings... Washington: NASA, 1974. v.1, p.309-317.

SMIGAJ, M.; GAULTON, R.; BARR, S. L.; SUÁREZ, J. C. Uav-Borne Thermal Imaging for Forest Health Monitoring: Detection of Disease-Induced Canopy Temperature Increase. In: THE INTERNATIONAL ARCHIVES OF THE PHOTOGRAMMETRY, REMOTE SENSING AND SPATIAL INFORMATION SCIENCES, 2015. La Grande Motte. Proceedings... La Grande Motte: France, 2015. Disponível em < https://www.int-arch-photogramm-remotesens-spatial-inf-sci.net/XL-3-W3/349/2015/ >. Acesso em: 17 dez. 2016.

SOUZA, A. A. DE; GALVÃO, L. S.; SANTOS, J. R. DOS. Índices de vegetação derivados do sensor Hyperion/EO-1 para estimativa de parâmetros biofísicos de fitofisionomias de Cerrado. In: SIMPÓSIO DE SENSORIAMENTO REMOTO, 14., 2009, Natal. Anais... Natal: UFRN, 2009. p 3095-3102.

Recebido em: 12/11/2017

Aceito em: 20/09/2018 